M.H. Shapiro", J.D. Melvin, T.A. Tombrello, Jiang Fong-liang**, Li Gui-ru**, M.H. Mendenhall, and A. Rice

W.K. Kellogg Radiation Laboratory, Caltech, Pasadena, California 91125

\title{
S. Epstein
}

Div. of Geological and Planetary Sciences, Caltech, Pasadena, California 91125

V.T. Jones, D. Masdea, and M. Kurtz

Gulf Science and Technology Company, P.0. Drawer 2038, Pittsburgh, Penna. 15230

\begin{abstract}
Correlations have been observed between groundwater radon and thoron

concentrations and carbon dioxide discharges at the Lake Hughes station of the Caltech radon monitoring network. The Lake Hughes site is one of three radon monitoring stations located near the "big bend" segment of the San Andreas fault which began to record anomalous radon levels in August 1981. Two stations, Lake Hughes and Lytle Creek, recorded anomalous increases in radon while the third, Sky Forest, recorded an anomalous decrease. Several weeks after the onset of the anomaly, strongly correlated radon fluctuations began at Lake Hughes and Lytle Creek. These radon spikes also were found to be phase anti-correlated with barometric pressure fluctuations. Analyses of gas grab samples showed relatively high levels of $\mathrm{CO}_{2}$ and ethylene in borehole air at Lake Hughes ${ }^{2}$ and Lytle Creek, while analyses of water samples showed relatively large increases in $\mathrm{HCO}_{3}{ }^{-}$at both sites. Isotopic analysis of one gas 3 sample from Lake Hughes yielded a ${ }^{9} \mathrm{C} \delta$ value of $-22 \%$, which suggests that the $\mathrm{CO}_{2}$ originates from the oxidation of organic material. The correlation in radon fluctuations at Lake Hughes and Lytle Creek and their common dependence on barometric pressure changes began shortly after the onset of the radon anomaly in August, and probably resulted from the simultaneous saturation of the water in these boreholes with carbon dioxide.
\end{abstract}

\section{Introduction}

The locations of the automated radon-thoron monitors operated by Caltech are shown in Figure 1. Four of the stations - Ft. Tejon, Lake Hughes, Lytle Creek, and Sky Forest - are in close proximity to the locked, "big bend" region of the San Andreas fault which has been accumulating strain since the $1857 \mathrm{Ft}$. Tejon earthquake. The

*Also affiliated with the Physics Department, California State University. Fullerton.

*** Permanent address: Institute of Geology, State Selsmological Bureau, Beijing, China.

Copyright 1982 by the American Geophysical Union.

Paper number 2L0473.

0094-8276/82/002L-0473\$3.00 remainder of the stations are located along the frontal faults of the Transverse Ranges. Melvin et al. [1978] have described the design and operation of the monitoring system, Shapiro et al. [1981 and references therein] have reported on data previously obtained from the network, and Jiang et al. [1981] have described the hydro-geological settings of the monitoring sites. From the inception of monitoring (1977), radon anomalies have been observed before some small, local earthquakes: and a major radon anomaly was observed starting in 1979 at two frontal fault stations (Kresge and Dalton Canyon) that appeared to be related to the strain event that has been associated with the $6.6 \mathrm{M}$ Imperial Valley earthquake (15 October 1979) and with the onset of increased seismicity in southern California [Shapiro et al., 1981].

Prior to August $1 \overline{98} 1$ the radon levels recorded by Caltech stations near the San Andreas fault have not appeared unusual. Lytle Creek, which is located near the junction of the San Andreas and San Jacinto faults, has been in operation the longest of the four stations. Data from that site (Figure 2) have shown a rather regular seasonal pattern with some sharp radon increases followed by even sharper decreases shortly after some more intense rainstorms in early 1980. A sharp increase in early 1981 followed the opening of the borehole to obtain some water samples. Except for one spike-like decrease in radon in October

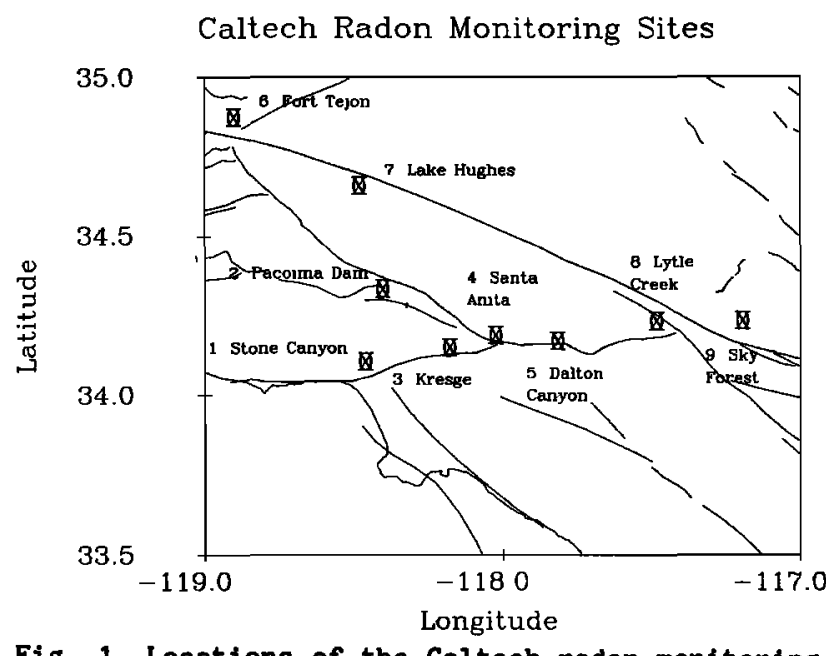

Fig. 1. Locations of the Caltech radon monitoring sites in southern California. 


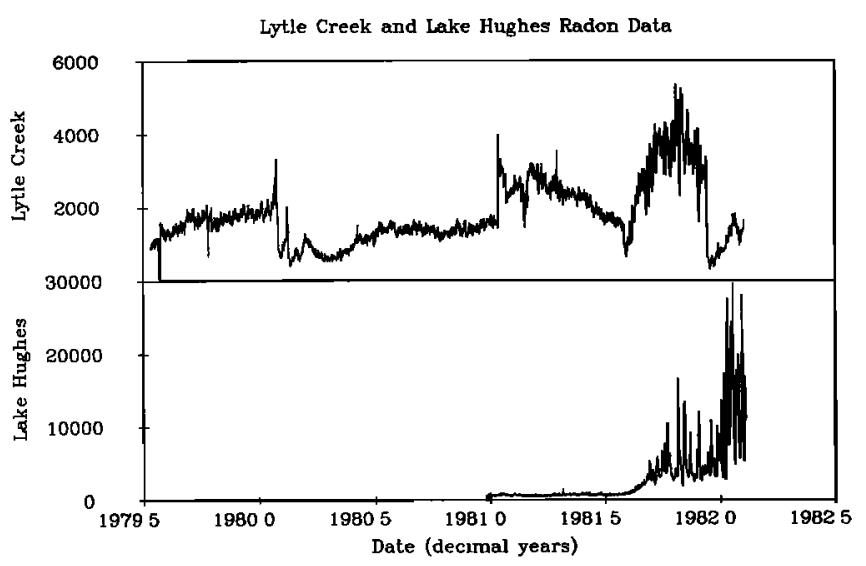

Fig. 2. Plots of Lytle Creek and Lake Hughes radon data.

1979 which we have attributed to a nearby $M=4.2$ event [Shapiro et al., 1981], the radon level at this site appeared to be governed largely by hydrological conditions through the beginning of 1981. At that time the radon level did not decrease with the winter rains as in previous years, but rather continued to increase until early March when it began a steady decline. The other stations near the San Andreas have not been in operation long enough for seasonal patterns to be determined, but the radon data from Lake Hughes, in particular, showed very little variation from the initiation of monitoring in late December 1980 until the onset of the anomaly.

\section{The Lake Hughes-Lytle Creek Radon Anomaly}

In early August 1981 the radon level at the Lake Hughes station began to increase substantially from its baseline of 800 counts/run. At the same time the Lytle Creek radon level (which had returned to near normal for late summer) decreased sharply, then also began to increase rapidly. Simultaneously, the radon level at Sky Forest, which had been decreasing for a few months, accelerated its decline. At the fourth San Andreas site, Ft. Tejon, no unusual changes were observed.

Initially, the increases at Lake Hughes and Lytle Creek were smooth, but after a month spikes in the radon level began at Lake Hughes, and similar but less pronounced fluctuations in radon level were observed from Lytle Creek (Figure 3 ). These fluctuations ranged in duration from one to a few days, and were correlated strongly in phase and amplitude (see the inset to Figure 3 ) although the two stations are located almost 100 $\mathrm{km}$ apart. The strength of the correlation suggested that a common, non-tectonic driving phenomenon was causing these simultaneous variations. A number of environmental factors were examined as possible causes for the correlation, and eventually a strong phase anti-correlation was found between barometric pressure and radon level at Lake Hughes. This result suggested that pressure changes were triggering some process that was causing more radon to be released from the groundwater.

This phase anti-correlation is illustrated in Figure 4 where both radon data from Lake Hughes and the negative of barometric pressure have been plotted. The time series in Figure 4 have been band-pass filtered to remove both diurnal variations and long-term trends from the data.

It should be noted that previous attempts to observe a correlation between changes in radon level and barometric pressure variations had produced essentially negative results. In particular, a study was made of the relationship between barometric pressure variations and the radon levels at Kresge in late 1978, where it was found that relatively large pressure increases accompanying Santa Ana wind conditions resulted in less than a $4 \%$ decrease in radon level. Likewise, no significant correlation between radon and barometric pressure changes was found for the 1979 Kresge radon anomaly.

\section{Analyses of Gas and Water Grab Samples}

At the same time that the barometric pressure relationship with the Lake Hughes - Lytle Creek data was being investigated, gas grab samples were obtained from the borehole air space at several of our monitoring sites. Analyses of these samples revealed that both Lake Hughes and Lytle Creek borehole air had become quite high in carbon dioxide and higher in ethylene in comparison to other sites of the network (see Table 1). Concentrations of other gases, however, did not appear unusual. These results suggested that $\mathrm{CO}_{2}$ evolving from the groundwater is carrying radon, and that the $\mathrm{CO}_{2}$ dissolved in the water is close enough to saturation that the equilibrium is highly pressure dependent.

Other geochemical measurements provide supporting evidence that an increase in carbonate concentration has taken place at the Lake Hughes site. Water samples were taken from the Lake Hughes borehole in January and April of 1981 (before and after the winter rains). The water was found to be of meteoric_origin and of the $\mathrm{HCO}_{3}-\mathrm{Ca}-\mathrm{Mg}$ type with a $\mathrm{HCO}_{3}{ }^{-}$concentration of about $130 \mathrm{mg} / \mathrm{l}$. This value was not altered significantly by the winter rainfall. After the onset of the Lake Hughes - Lytle Creek anomaly

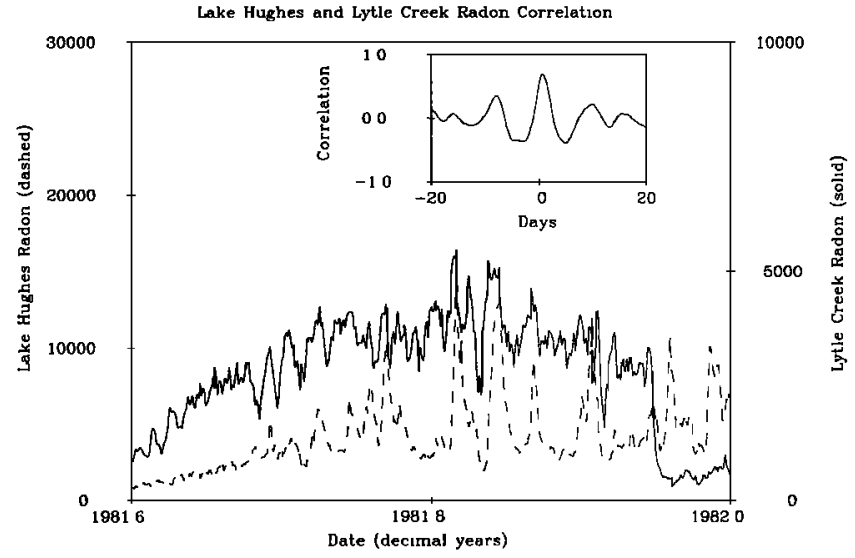

Fig. 3. Expanded plot of Lytle Creek and Lake Hughes radon data. A correlogram of the data is shown in the inset figure. The data were high pass filtered with $1 / \mathrm{e}$ rolloff at 30 days. Oniy data between 1981.60 and 1981.89 were cross-correlated. 
Table 1. Gas Analysis of Borehole Air from the Caltech Radon Monitoring Network (Samples collected between 13 October and 20 October 1981)

\begin{tabular}{|c|c|c|c|c|c|}
\hline$\overline{\text { SAMPLE }}$ & $\begin{array}{l}\text { METHANE } \\
\text { (PPB) }\end{array}$ & $\begin{array}{c}\text { ETHYLENE } \\
\text { (PPB) }\end{array}$ & $\begin{array}{l}\text { HELIUM } \\
\text { (PPM) }\end{array}$ & $\begin{array}{l}\text { HYDROGEN } \\
\text { (PPM) }\end{array}$ & $\begin{array}{l}\text { CARBON DIOXIDE } \\
\text { (VOL } \% \text { ) }\end{array}$ \\
\hline $\begin{array}{l}\text { AMBIENT AIR } \\
\text { e SKY FOREST }\end{array}$ & 2385 & 1 & 6 & 0 & 0.03 \\
\hline $\begin{array}{ll}\text { SKY FOREST } & \# 1 \\
\text { SKY FOREST } & \end{array}$ & $\begin{array}{l}2431 \\
2431\end{array}$ & $\begin{array}{l}6 \\
7\end{array}$ & $\begin{array}{l}6 \\
6\end{array}$ & $\begin{array}{l}\mathbf{0} \\
0\end{array}$ & $\begin{array}{l}0.02 \\
0.02\end{array}$ \\
\hline 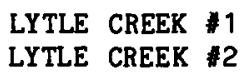 & $\begin{array}{l}2274 \\
2284\end{array}$ & $\begin{array}{l}63 \\
57\end{array}$ & $\begin{array}{l}6 \\
6\end{array}$ & $\begin{array}{l}0 \\
0\end{array}$ & $\begin{array}{l}0.30 \\
0.29\end{array}$ \\
\hline $\begin{array}{l}\text { DALTON } \# 1 \\
\text { DALTON } \# 2 \\
\text { DALTON } \# 3\end{array}$ & $\begin{array}{r}994 \\
1004 \\
1197\end{array}$ & $\begin{array}{l}3 \\
4 \\
7\end{array}$ & $\begin{array}{l}6 \\
6 \\
6\end{array}$ & $\begin{array}{l}0 \\
0 \\
0\end{array}$ & $\begin{array}{l}0.07 \\
0.11 \\
0.06\end{array}$ \\
\hline $\begin{array}{l}\text { KRESGE } \# 1 \\
\text { KRESGE } \# 2\end{array}$ & $\begin{array}{l}2431 \\
2431\end{array}$ & $\begin{array}{l}18 \\
18\end{array}$ & $\begin{array}{l}6 \\
6\end{array}$ & $\begin{array}{l}6 \\
6\end{array}$ & $\begin{array}{l}0.16 \\
0.15\end{array}$ \\
\hline $\begin{array}{l}\text { STONE CAN. \#1 } \\
\text { STONE CAN. \#2 }\end{array}$ & $\begin{array}{l}2615 \\
2615\end{array}$ & $\begin{array}{l}36 \\
37\end{array}$ & $\begin{array}{l}6 \\
6\end{array}$ & $\begin{array}{l}3 \\
3\end{array}$ & $\begin{array}{l}0.20 \\
0.18\end{array}$ \\
\hline $\begin{array}{l}\text { PACOIMA } \# 1 \\
\text { PACOIMA } \# 2\end{array}$ & $\begin{array}{l}1418 \\
1409\end{array}$ & $\begin{array}{l}24 \\
25\end{array}$ & $\begin{array}{l}6 \\
6\end{array}$ & $\begin{array}{l}3 \\
4\end{array}$ & $\begin{array}{l}0.32 \\
0.28\end{array}$ \\
\hline $\begin{array}{l}\text { LAKE HUGHES } \# 1 \\
\text { LAKE HUGHES } \# 2\end{array}$ & $\begin{array}{l}2505 \\
2486\end{array}$ & $\begin{array}{r}118 \\
69\end{array}$ & $\begin{array}{l}6 \\
6\end{array}$ & $\begin{array}{l}0 \\
0\end{array}$ & $\begin{array}{l}0.50 \\
0.40\end{array}$ \\
\hline
\end{tabular}

additional water samples were taken from three wells close to the Lake Hughes borehole. These samples all yielded $\mathrm{HCO}_{3}^{-}$values near $300 \mathrm{mg} / 1$. While the latter value is not exceptionally high in relation to the $\mathrm{HCO}_{3}{ }^{-}$concentrations at some of our other sites, it does represent a much larger change than we have seen elsewhere in the network.

Isotopic analyses of one of the gas samples from Lake Hughes has been carried out to determine the ${ }^{3} \mathrm{C} /{ }^{12} \mathrm{C}$ ratio in an attempt to learn the origin of the $\mathrm{CO}_{2}$. The resulting $\delta$ value of about $-22 \%$ is compatible with $\mathrm{CO}_{2}$ production by the oxidation of organic material such as petroleum [Zartman, et al., 1961]. The isotopic analysis of oxygen from the same sample confirmed that the water is of meteoric origin.

\section{Continuous $\mathrm{CO}_{2}$ Measurements}

Shortly after the results of the gas grab sample analyses became available, a continuous $\mathrm{CO}_{2}$ monitor was installed at Lake Hughes to measure the carbon dioxide concentration in the borehole airspace. This instrument was interfaced to the radon monitor in such a way that the carbon dioxide concentration in the borehole airspace could be measured shortly after the well is stripped of radon by the operation of a bubbler. The results are shown in Figure 5 . Generally, there is a good correlation between changes in $\mathrm{CO}_{2}$ concentration and radon spikes. Careful examination of the data has shown that increases in $\mathrm{CO}_{2}$ lead the radon (half-life $=3.8$ days) spikes by almost one day, while corresponding peaks in thoron (half-life $=55$ sec) occur almost simultaneously with $\mathrm{CO}_{2}$. In part, this is an instrumental effect since the radon monitors aqtually are sensitive to the radon daughters ${ }^{214} \mathrm{~Pb}$ and ${ }^{214} \mathrm{Bi}$ which grow in as the radon decays. However, in part the delay may indicate that $\mathrm{CO}_{2}$ is sweeping radon from a fairly large volume of rock.

\section{Discussion}

Several points can be made regarding the observations reported in this paper. First, the

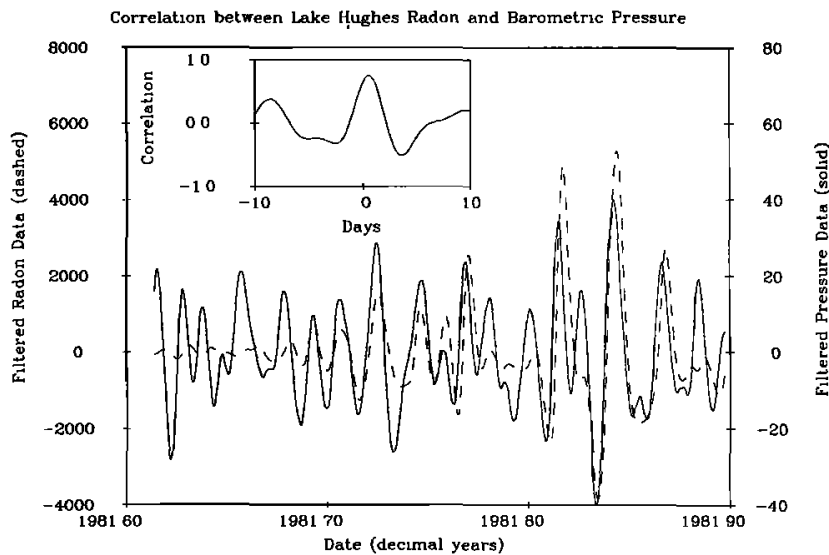

Fig. 4. Comparison of Lake Hughes radon data with barometric pressure data. Both the radon and pressure data have been band-pass filtered to remove long-term trends and diurnal variations. (1/e rolloffs at 1 day and 15 days.) Pressure data are in (mb - 1000) and they have been multiplied by -1 to facilitate comparison. A correlogram resulting from cross-correlation of the filtered data between 1981.65 and 1981.95 is shown in the insert. 


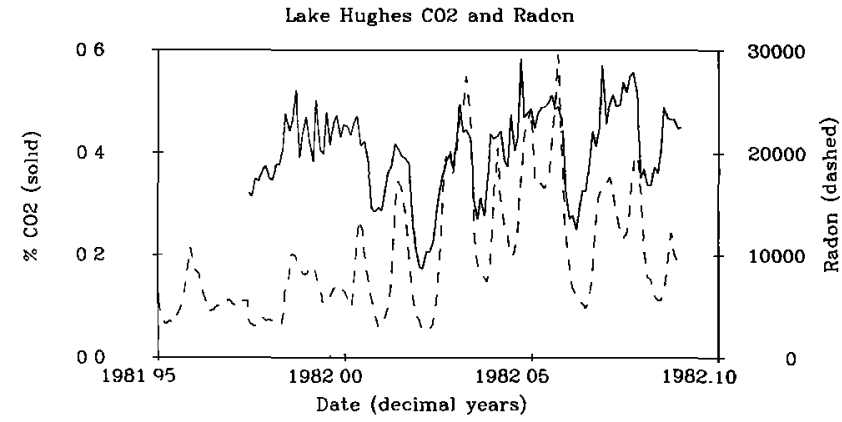

Fig. 5. Comparison of Lake Hughes radon with carbon dioxide concentration.

strong amplitude and phase correlation between radon spikes at Lake Hughes and Lytle Creek almost certainly is the result of barometric pressure changes triggering bubbling in these boreholes. Second, the major gas component being released is carbon dioxide. Third, isotopic analysis suggests that the carbon dioxide is of organic origin. Fourth, this situation represents a significant change from the previous geochemical/geophysical regime.

From Table 1 it can been seen that the Kresge, Pacoima, and Stone Canyon station exhibit $\mathrm{CO}_{2}$ levels in borehole air that are relatively high? however, these sites are located at considerably lower elevation than Lake Hughes and Lytle Creek, which probably explains the absence of pressure induced bubbling at those sites.

The tectonic implications of these data are far from clear. Irwin and Barnes [1980] have found a close connection between high $\mathrm{CO}_{2}$ concentrations in wells and springs and tectonic regions. Both radon and $\mathrm{CO}_{2}$ anomalies frequently have been reported before moderate and large earthquakes, and the "big bend" segment of the San Andreas has accumulated sufficient strain energy to initlate a major earthquake. However, as Irwin and Barnes [1980] have noted, changes in $\mathrm{CO}_{2}$ concentrations may begin long before failure occurs. At this time, surface strain measurements at a location about half-way between Lake Hughes and Lytle Creek [Langbein, private communication] have not shown any unusual recent changes.
However, the anomalies in radon and $\mathrm{CO}_{2}$ may be indicative of relatively subtle 2 tectonic processes. Certainly, further careful monitoring is warranted.

The observation of significant "spike-like" radon anomalies of short duration before some major earthquakes [Teng, 1980] has been difficult to understand in terms of conventional models of radon emanation and transport by groundwater. Our results suggest that these radon "spikes" could result from major gas components sweeping out radon relatively quickly from an aquifer.

Acknowledgments. The work in this paper was supported in part by U.S. Geological Survey Contract 14-08-0001-19752 at Caltech. We thank the Earth Sciences Department at California State University, Fullerton for providing microbarograph data.

\section{References}

Irwin, W.P. and I. Barnes, Tectonic relations of carbon dioxide discharges and earthquakes, $J$. Geophys. Res., 85, 3115, 1980.

Jiang, Fong-liang, Li Gui-ru, J.D. Melvin, M.H. Shapiro, and T.A. Tombrello, Seismo-geochemical characteristics of the Caltech radon-thoron monitoring network, Eos, 62, 963, 1981.

Melvin, J.D., M.H. Shapiro, and N.A. Copping, An automated radon-thoron monitor for earthquake prediction research, Nucl. Instrum. and Methods, 153, 239, 1978.

Shapiro, M.H., J.D. Melvin, T.A. Tombrello, M.H. Mendenhall, P.B. Larson, and J.H. Whitcomb, Relationship of the 1979 southern California radon anomaly to a possible regional strain event, J. Geophys. Res., 86, 1725, 1981.

Teng, T., Some recent studies on groundwater radon content as an earthquake precursor, $\mathrm{J}$. Geophys. Res.. 85, 3089, 1980.

Zartman, R.E.. G.J. Wasserburg, and J.H. Reynolds, Helium, argon, and carbon in some natural gases, J. Geophys. Res., 66, 277, 1961.

(Received February 9, 1982 accepted March 15, 1982.) 